\title{
Arterial graft deterioration one year after coronary artery bypass grafting
}

\author{
Susumu Manabe, MD, ${ }^{\text {a }}$ Toshihiro Fukui, MD, ${ }^{\text {a }}$ Minoru Tabata, MD,${ }^{\mathrm{a}}$ Tomoki Shimokawa, MD, ${ }^{\mathrm{a}}$ \\ Satoshi Morita, MD, $\mathrm{PhD},{ }^{\mathrm{b}}$ and Shuichiro Takanashi, $\mathrm{MD}^{\mathrm{a}}$
}

\begin{abstract}
Objective: Some arterial grafts have progressive narrowing or occlusion during the first postoperative year despite angiographic patency in the immediate postoperative period. This study analyzed the incidence and predictors of arterial graft deterioration.
\end{abstract}

\begin{abstract}
Methods: We reviewed 778 distal anastomoses of arterial grafts in 243 patients who underwent off-pump coronary artery bypass grafting. All patients underwent both early and 1-year follow-up coronary angiography, with all arterial grafts patent on the early angiograms. Arterial graft deterioration was defined as diffuse graft stenosis or occlusion newly found at 1-year follow-up angiography.

Results: Graft deterioration was present in $13.8 \%$ (string sign, $6.9 \%$; occlusion, $6.8 \%$ ) of distal anastomoses. The incidence of graft deterioration was higher among cases of non-internal thoracic arterial graft $(27.7 \% \mathrm{vs} 6.0 \%$, $P<.001)$, non-left anterior descending coronary arterial anastomosis $(19.1 \%$ vs $2.0 \%, P<.001)$, mild $(\leq 75 \%)$ stenosis of the target coronary artery $(26.0 \%$ vs $7.6 \%, P<.001)$, composite grafting $(19.9 \%$ vs $7.8 \%, P<.001)$, and multiple anastomoses from a single inflow source $(19.5 \%$ vs $5.1 \%, P<.001)$. The incidence was particularly high when composite or multiple grafting from a single inflow source was performed to a target coronary artery with mild stenosis. Non-internal thoracic arterial graft, mild target stenosis, and multiple grafting from a single inflow source were independent predictors of graft deterioration.
\end{abstract}

Conclusions: Arterial graft deterioration was closely related to particular graft materials and designs. (J Thorac Cardiovasc Surg 2010;140:1306-11)

The survival benefit of using a single internal thoracic artery (ITA) in coronary artery bypass grafting (CABG) was demonstrated in the mid 1980s, ${ }^{1}$ and further beneficial effects of additional arterial graft use have been subsequently reported in several studies. ${ }^{2-4}$ The clinical benefits provided by an arterial graft are usually considered to be related to superior patency. ${ }^{5,6}$ The early failure of an arterial graft is rare and is related to several mechanisms, including anastomotic problems and poor quality of the graft material or the native coronary artery. Some arterial grafts, however, fail during the first year. Several studies have reported that some arterial grafts occlude in this time period, and this may result from competition with native coronary flow. ${ }^{7,8}$ Other arterial grafts are reduced in caliber and show diffuse narrowing, the string sign. The incidence of string sign has not been negligible in some previous studies. ${ }^{9,10}$ These findings suggest that some

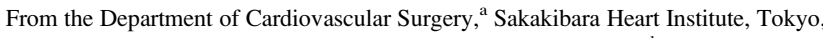
Japan, and the Department of Biostatistics and Epidemiology, ${ }^{\mathrm{b}}$ Yokohama City University, Yokohama, Japan.

Disclosures: None.

Received for publication April 2, 2009; revisions received Nov 26, 2009; accepted for publication Jan 1, 2010; available ahead of print March 26, 2010.

Address for reprints: Susumu Manabe, MD, Department of Cardiovascular Surgery, Sakakibara Heart Institute, Asahicho 3-16-1, Fuchu, Tokyo 183-0003, Japan (E-mail: s-manabe@fb3.so-net.ne.jp).

$0022-5223 / \$ 36.00$

Copyright (c) 2010 by The American Association for Thoracic Surgery doi:10.1016/j.jtcvs.2010.01.009
}

arterial grafts may lose the ability to function as a bypass conduit as a result of graft deterioration. In this study we therefore analyzed the incidence, predictors, and clinical consequences of arterial graft deterioration 1 year after CABG.

\section{MATERIALS AND METHODS Study Design}

In this retrospective cohort study, we first examined a series of follow-up angiograms performed before discharge and 1 year after surgery and then investigated the predictors of arterial graft deterioration. In addition, we investigated the association between arterial graft deterioration and clinical outcomes. The Ethics Committee of Sakakibara Heart Institute approved this study, waived the need for patient consent, and provided approval before publication of the data.

\section{Study Subjects and Data Collection}

Between September 2004 and July 2007, a total of 536 patients underwent isolated $\mathrm{CABG}$ at our institution. All patients were scheduled for off-pump CABG. Twenty-five emergency cases were included. Six patients who had conversion to on-pump CABG were excluded from the study. We routinely performed coronary angiography before discharge and 1 year after surgery for patients who underwent off-pump CABG, regardless of the patient's symptoms. Patients who died, refused angiographic evaluation, were older than 75 years, or had renal dysfunction (serum creatinine $>1.2$ $\mathrm{mg} / \mathrm{dL}$ ) were excluded from the angiographic follow-up. Of the 536 patients, 432 underwent early angiography and 273 underwent 1-year follow-up angiography. For early angiography before discharge, 67 patients were excluded for old age, 15 were excluded for renal dysfunction, and 22 were excluded for patient refusal. For follow-up angiography at 1 year after surgery, 113 patients were excluded for old age, 24 were excluded 


\section{Abbreviations and Acronyms}

$\mathrm{CABG}=$ coronary artery bypass grafting

ITA $=$ internal thoracic artery

$\mathrm{LAD}=$ left anterior descending artery

for renal dysfunction, and 126 were excluded for patient refusal. A total of 256 patients $(47.8 \%)$ underwent both early and 1-year follow-up angiography. The angiographic results of these patients are shown in Table 1. Thirteen patients with multiple arterial grafting who had at least 1 occluded anastomosis were excluded from the study. Findings of the remaining 243 patients were retrospectively reviewed.

Perioperative clinical data were collected from patient medical records. All patients were followed up for at least 1 year, and mean follow-up was 21.8 months. A major adverse cardiac event was defined as the occurrence of a nonfatal myocardial infarction, the need for repeat revascularization, or cardiac death. Cardiac death was defined as death occurring in relation to myocardial infarction, cardiac arrhythmia, out-of-hospital sudden cardiac death, or deteriorating congestive heart failure. Undetermined causes of death were assumed to be cardiac.

One cardiologist initially reviewed all the coronary angiograms, and a consensus was reached among the surgical team after review. For native coronary arteries, mild stenosis was defined as a stenotic lesion of $75 \%$ or less. Distal anastomoses were assessed and classified as patent, focally stenosed, string sign, or occluded. A focally stenosed lesion was defined as one with a focal stenosis of $90 \%$ or greater anywhere within the conduit or at the anastomosis. String sign was defined as luminal narrowing throughout the entire conduit, including stenosis of $90 \%$ or greater. Each distal anastomosis represented a separate data point in the analysis. The patency rate was calculated as the number of distal anastomoses without occlusion per total distal anastomoses. Patent graft anastomosis included grafts with focal stenosis or string sign. Arterial graft deterioration was defined as a graft that had been patent on the early angiogram but appeared occluded or showed evidence of string sign on the 1-year angiogram. The incidence of arterial graft deterioration was calculated as the rate of distal anastomoses with arterial graft deterioration per total distal anastomoses.

\section{Operative Strategy}

Our surgical procedures and principles of off-pump CABG have been previously described. ${ }^{11}$ The left-sided coronary arteries were revascularized with arterial grafts in most cases. The left anterior descending artery (LAD) was revascularized exclusively with the ITA, and the left ITA was used preferentially. The right ITA was revascularized to the LAD only when the left
ITA was required to bypass a remote anastomotic site of the left circumflex artery. The most frequently used arrangement for diagonal artery and left circumflex artery was composite grafting with right ITA and radial artery. In this arrangement, the right ITA was used as an in situ graft for the diagonal, and the radial artery was anastomosed proximally to the right ITA and distally to the left circumflex artery. The right coronary artery was grafted with saphenous vein or gastroepiploic artery in most cases. Use of the gastroepiploic artery was usually limited to patients with severe stenosis of the right coronary artery. Grafts used in 242 study patients are shown in Table 2.

Aspirin $(81 \mathrm{mg})$ was given to all patients before and after surgery. In 66 cases, ticlopidine hydrochloride (INN ticlopidine) was given for 1 month. Heparin $(3.0 \mathrm{mg} / \mathrm{kg})$ was administered intravenously after sternotomy, and it was neutralized at the end of the procedure with protamine sulfate $(3.0 \mathrm{mg} / \mathrm{kg})$. All radial arteries and saphenous veins were harvested open. The radial artery was soaked in a solution $(20 \mathrm{mg}$ olprinone plus $180 \mathrm{~mL}$ normal saline solution). After hemostasis was confirmed, all patients received a continuous heparin infusion until the second postoperative day. Patients with a radial artery graft received continuous administration of intravenous diltiazem during the first 24 hours after surgery.

\section{Statistical Analysis}

Continuous variables are reported as mean $\pm \mathrm{SD}$ and categorical variables as percentages. Fisher's Exact test was used to compare categorical variables The Mann-Whitney test was used to compare continuous variables. Actuarial and event-free survival curves were obtained with the Kaplan-Meier method. Statistical significance was calculated with the log-rank test. Multivariate analysis was performed to identify independent risk factors for arterial graft deterioration. A generalized estimating equation method was used to account for within-patient correlation. Predictors were discarded at a $P$ value greater than .10. Covariates included in the generalized estimating equation models were graft material (ITA vs non-ITA), stenosis rate of target coronary artery (mild vs more than mild), and number of distal anastomoses from a single inflow source (single vs multiple). Target coronary artery (LAD vs nonLAD) and graft configuration (individual vs composite graft) were discarded, because LAD was grafted with ITA exclusively and composite grafting was involved in multiple grafting. Odds ratios were calculated with $95 \%$ confidence intervals. All statistical analyses were performed with SPSS statistical software (SPSS version 17.0; SPSS Japan, Tokyo, Japan).

\section{RESULTS}

\section{Characteristics of Study Patients}

The preoperative characteristics of study patients were compared with those of the patients excluded from the study (Table 3). There were significant differences between the

TABLE 1. Angiographic results for early and 1-year patencies

\begin{tabular}{|c|c|c|c|c|c|c|c|c|c|c|c|}
\hline & \multirow[b]{3}{*}{ Distal anastomoses } & \multicolumn{5}{|c|}{ Early } & \multicolumn{5}{|c|}{$1 \mathrm{y}$} \\
\hline & & \multirow[b]{2}{*}{ Patency $(\%)$} & \multicolumn{4}{|c|}{ Stenosis (no.) } & \multirow[b]{2}{*}{ Patency $(\%)$} & \multicolumn{4}{|c|}{ Stenosis (no.) } \\
\hline & & & PP & FS & SS & $\mathrm{CO}$ & & PP & FS & SS & $\mathrm{CO}$ \\
\hline All arteries & 830 & $97.5 \%$ & 796 & 13 & 0 & 21 & $90.8 \%$ & 689 & 8 & 57 & 76 \\
\hline \multicolumn{12}{|l|}{ Internal thoracic artery } \\
\hline Any & 527 & $99.1 \%$ & 512 & 10 & 0 & 5 & $96.8 \%$ & 486 & 5 & 19 & 17 \\
\hline Left & 292 & $98.6 \%$ & 279 & 9 & 0 & 4 & $97.3 \%$ & 279 & 4 & 1 & 8 \\
\hline Right & 235 & $99.6 \%$ & 233 & 1 & 0 & 1 & $96.2 \%$ & 207 & 1 & 18 & 9 \\
\hline Radial artery & 260 & $93.9 \%$ & 242 & 2 & 0 & 16 & $78.9 \%$ & 170 & 2 & 33 & 55 \\
\hline Gastroepiploic artery & 43 & $100 \%$ & 42 & 1 & 0 & 0 & $90.7 \%$ & 33 & 1 & 5 & 4 \\
\hline Saphenous vein & 220 & $96.8 \%$ & 212 & 1 & 0 & 7 & $81.8 \%$ & 169 & 10 & 1 & 40 \\
\hline
\end{tabular}

$P P$, Perfectly patent; $F S$, focally stenosed; $S S$, string sign; $C O$, completely occluded. 
TABLE 2. Number of distal anastomoses for each graft type according to target coronary artery

\begin{tabular}{lcccr}
\hline & \multicolumn{4}{c}{ Target coronary artery } \\
\cline { 2 - 5 } Conduit & $\begin{array}{c}\text { Left anterior } \\
\text { descending }\end{array}$ & Diagonal & $\begin{array}{c}\text { Left } \\
\text { circumflex }\end{array}$ & Right \\
\hline Left internal thoracic artery & & & \\
All & 198 & 20 & 60 & 0 \\
Individual & 167 & 15 & 39 & 0 \\
Composite & 31 & 5 & 21 & 0 \\
Right internal thoracic artery & & & \\
All & 46 & 104 & 72 & 0 \\
Individual & 43 & 23 & 32 & 0 \\
Composite & 3 & 81 & 40 & 0 \\
Radial artery & & & & \\
All & 0 & 37 & 183 & 19 \\
Individual & 0 & 10 & 30 & 6 \\
Composite & 0 & 27 & 153 & 13 \\
Gastroepiploic artery & & & & \\
All & 0 & 3 & 6 & 30 \\
Individual & 0 & 1 & 1 & 29 \\
Composite & 0 & 2 & 5 & 1 \\
Saphenous vein & & & & \\
All & 0 & 1 & 17 & 196 \\
Individual & 0 & 0 & 6 & 187 \\
Composite & 0 & & & 9 \\
\hline
\end{tabular}

groups in age, sex, and the prevalence of hypertension. Midterm clinical results were also compared between these groups (Table 3). The 2-year survival of study patients was significantly higher than that of excluded patients.

TABLE 3. Comparison of patient characteristics and midterm clinical results between study patients and excluded patients

\begin{tabular}{lccc}
\hline & $\begin{array}{c}\text { Study } \\
(\mathbf{n}=\mathbf{2 4 3})\end{array}$ & $\begin{array}{c}\text { Excluded } \\
(\mathbf{n = 2 8 0})\end{array}$ & $\boldsymbol{P}$ value \\
\hline Preoperative & & & \\
Age (y, mean \pm SD) & $66.6 \pm 7.7$ & $71.0 \pm 9.3$ & $<.001$ \\
Male (no.) & $243(86.0 \%)$ & $216(77.1 \%)$ & .01 \\
Coronary risk factor (no.) & & & \\
$\quad$ Hypertension & $172(70.8 \%)$ & $220(78.6 \%)$ & .043 \\
$\quad$ Diabetes & $99(40.7 \%)$ & $111(39.6 \%)$ & .858 \\
Hyperlipidemia & $153(63.0 \%)$ & $156(55.7 \%)$ & .108 \\
Smoking & $137(56.4 \%)$ & $152(54.3 \%)$ & .660 \\
Old cerebral infarct (no.) & $18(7.4 \%)$ & $32(11.4 \%)$ & .137 \\
Peripheral vascular disease (no.) & $13(5.4 \%)$ & $28(10.0 \%)$ & .052 \\
Long-term hemodialysis (no.) & $9(3.7 \%)$ & $10(3.6 \%)$ & 1.00 \\
Midterm clinical results & & & \\
Follow-up rate (\%) & $100.0 \%$ & $94.6 \%$ & \\
Follow-up period (d, mean \pm SD) & $654 \pm 321$ & $521 \pm 408.9$ & $<.001$ \\
Survival (\%) & & & $<.001$ \\
1 y & $100.0 \%$ & $95.4 \%$ & \\
2 y & $100.0 \%$ & $93.2 \%$ & \\
Major adverse cardiac event-free survival (\%) & & .897 \\
1 y & $96.3 \%$ & $95.5 \%$ & \\
2 y & $91.4 \%$ & $92.9 \%$ & \\
\hline
\end{tabular}

\section{Angiographic Outcomes}

Arterial graft deterioration was seen in 74 patients. Patient characteristics were compared between patients with and without deterioration of grafts (Table 4). There were no differences in preoperative patient characteristics and postoperative medications between these groups.

The incidence of arterial graft deterioration was 13.8\% (107/778 distal anastomoses). In univariate analysis, the incidences of graft deterioration were significantly higher for non-ITA grafts $(27.7 \%$ vs $6.0 \%, P<.001)$, non-LAD anastomoses $(19.1 \%$ vs $2.0 \%, P<.001)$, mild $(\leq 75 \%)$ stenosis of target coronary arteries $(26.0 \%$ vs $7.6 \%, P<.001)$, composite grafting $(19.9 \%$ vs $7.8 \%, P<.001)$, and multiple anastomoses from a single inflow source $(19.5 \%$ vs $5.1 \%$, $P<.001$; Table 5). The results of multivariate analysis are shown in Table 6. Non-ITA graft, mild target stenosis, and multiple grafting from a single inflow source were the independent predictors of graft deterioration. Figure 1 shows the effects of graft configuration and number of distal anastomoses from a single inflow source on the incidence of arterial graft deterioration according to the severity of target coronary artery stenosis. The differences in the incidence of graft deterioration according to graft configurations or numbers of distal anastomoses were much greater for target arteries with mild stenosis than for those with severe stenosis. For targets with mild stenosis, composite and multiple grafting from a single inflow source resulted in a high incidence of arterial graft deterioration.

\section{Clinical Outcomes}

The recurrence of angina symptoms was significantly greater among patients with graft deterioration than among

TABLE 4. Patient characteristics and postoperative medications

$\frac{\text { Deterioration }}{\text { No }(n=169) \text { Yes }(n=74)} P$ value

\begin{tabular}{lccc}
\hline Preoperative & & & \\
Age (y, mean \pm SD) & $66.7 \pm 7.5$ & $66.3 \pm 8.2$ & .909 \\
Male (no.) & $142(84.0 \%)$ & $67(90.5 \%)$ & .229 \\
Coronary risk factor (no.) & & & \\
$\quad$ Hypertension & $118(69.8 \%)$ & $54(73.0 \%)$ & .649 \\
$\quad$ Diabetes & $74(43.8 \%)$ & $25(33.8 \%)$ & .158 \\
$\quad$ Hyperlipidemia & $106(62.7 \%)$ & $47(63.5 \%)$ & $>.999$ \\
$\quad$ Smoking & $14(8.3 \%)$ & $4(5.4 \%)$ & .596 \\
Old cerebral infarct (no.) & $7(4.1 \%)$ & $6(8.1 \%)$ & .224 \\
Peripheral vascular disease (no.) & $9(5.3 \%)$ & $0(0 \%)$ & \\
Long-term hemodialysis (no.) & & & \\
Postoperative medication (no.) & $72(42.6 \%)$ & $39(52.7 \%)$ & .163 \\
$\beta$-Blocker & $57(33.7 \%)$ & $23(31.1 \%)$ & .767 \\
Statin & $11(6.5 \%)$ & $5(6.8 \%)$ & $>.999$ \\
Angiotensin-converting enzyme & & & \\
inhibitor & $35(20.7 \%)$ & $15(20.3 \%)$ & $>.999$ \\
Angiotensin receptor blocker & $31(18.3 \%)$ & $8(10.8 \%)$ & .184 \\
Calcium blockade & $111(65.7 \%)$ & $49(66.2 \%)$ & $>.999$ \\
\hline Warfarin & & & \\
\hline
\end{tabular}


TABLE 5. Prevalences of arterial graft deterioration

\begin{tabular}{|c|c|c|c|c|c|}
\hline Predictor & Total & Deteriorated & Occluded & String & $P$ value \\
\hline \multicolumn{5}{|l|}{ Conduit } & $<.001$ \\
\hline Internal thoracic artery & 500 & $30(6.0 \%)$ & $12(2.4 \%)$ & $18(3.6 \%)$ & \\
\hline Left & 278 & $5(1.8 \%)$ & $4(1.4 \%)$ & $1(0.4 \%)$ & \\
\hline Right & 222 & $25(11.3 \%)$ & $8(3.6 \%)$ & $17(7.7 \%)$ & \\
\hline Non-internal thoracic artery & 278 & $77(27.7 \%)$ & $41(14.8 \%)$ & $36(13.0 \%)$ & \\
\hline Radial artery & 239 & $69(28.9 \%)$ & $38(15.9 \%)$ & $31(13.0 \%)$ & \\
\hline Gastroepiploic artery & 39 & $82(0.5 \%)$ & $3(7.7 \%)$ & $5(12.8 \%)$ & \\
\hline \multicolumn{5}{|l|}{ Target coronary artery } & $<.001$ \\
\hline Left anterior descending & 244 & $5(2.0 \%)$ & $3(1.2 \%)$ & $2(0.8 \%)$ & \\
\hline Non-left anterior descending & 534 & $102(19.1 \%)$ & $50(9.4 \%)$ & $52(9.7 \%)$ & \\
\hline Diagonal & 164 & $19(11.6 \%)$ & $9(5.5 \%)$ & $10(6.1 \%)$ & \\
\hline Left circumflex & 321 & $74(23.1 \%)$ & $36(11.2 \%)$ & $38(11.8 \%)$ & \\
\hline Right & 49 & $9(18.4 \%)$ & $5(10.2 \%)$ & $4(8.2 \%)$ & \\
\hline \multicolumn{5}{|l|}{ Stenosis of target coronary artery } & $<.001$ \\
\hline More than mild (>75\%) & 516 & $39(7.6 \%)$ & $19(3.7 \%)$ & $20(3.9 \%)$ & \\
\hline Mild $\geq 75 \%$ & 262 & $68(26.0 \%)$ & $34(13.0 \%)$ & $34(13.0 \%)$ & \\
\hline \multicolumn{5}{|l|}{ Graft configuration } & $<.001$ \\
\hline Individual & 396 & $31(7.8 \%)$ & $15(3.8 \%)$ & $16(4.0 \%)$ & \\
\hline Composite & 382 & $76(19.9 \%)$ & $38(9.9 \%)$ & $38(9.9 \%)$ & \\
\hline \multicolumn{5}{|c|}{ No. of distal anastomoses from single inflow source } & $<.001$ \\
\hline 1 & 16 & $312(5.1 \%)$ & $6(1.9 \%)$ & $10(3.2 \%)$ & \\
\hline$\geq 2$ & 466 & $91(19.5 \%)$ & $47(10.1 \%)$ & $44(9.4 \%)$ & \\
\hline 2 & 173 & $31(17.9 \%)$ & $18(10.4 \%)$ & $13(7.5 \%)$ & \\
\hline 3 & 206 & $39(18.9 \%)$ & $14(6.8 \%)$ & $25(12.1 \%)$ & \\
\hline 4 or 5 & 87 & $21(24.1 \%)$ & $15(17.2 \%)$ & $6(6.9 \%)$ & \\
\hline
\end{tabular}

All data represent numbers of grafts.

those without graft deterioration $(9.5 \%$ vs $3.0 \%, P=.049)$. The incidence of major adverse cardiac events tended to be higher among patients with graft deterioration, but the difference was not statistically significant $(13.5 \%$ vs $6.5 \%$, $P=.104)$.

\section{DISCUSSION}

\section{Arterial Graft Deterioration}

In this study, we focused on arterial grafts that had been patent immediately after surgery and became occluded or diffusely narrowed during the first postoperative year. Most previous studies have used patency rate as an index of the graft function, and the patency rates in our study were comparable with those in previous studies. ${ }^{12,13} \mathrm{We}$ also treated string sign as graft dysfunction, and the incidence of string sign was nearly identical to that of graft occlusion. There is still some debate whether graft occlusion and string sign have to be viewed in a similar

TABLE 6. Results of multivariate analysis

\begin{tabular}{lccr}
\hline \multicolumn{1}{c}{ Predictor } & Odds ratio & interval & $\boldsymbol{P}$ value \\
\hline Non-internal thoracic artery graft & 5.05 & $2.79-9.13$ & $<.001$ \\
Mild target stenosis & 4.52 & $2.77-7.37$ & $<.001$ \\
Multiple grafting from & 2.68 & $1.37-5.25$ & .004 \\
$\quad$ single inflow source & & & \\
\hline
\end{tabular}

manner. It was sometimes difficult to discriminate clearly between grafts showing string sign and those showing occlusion, however, because some grafts appeared to be intermediate between these states. Graft occlusion and string sign were sometimes intermingled in the same graft, and some grafts were halfway patent, showing string sign and occlusion in the latter half. Moreover, the prevalence and predictors were nearly identical for graft occlusion and string sign. In this study, string sign and graft occlusion were therefore similarly viewed as evidence of a deteriorated graft.

\section{Predictors of Graft Deterioration}

Our study revealed several predictors of arterial graft deterioration 1 year after CABG. Mild stenosis of the target coronary artery was an independent predictor of graft deterioration. Other studies have also shown mild stenosis to be an independent predictor of graft occlusion ${ }^{8}$ or string sign. ${ }^{14,15}$ Graft material was also an independent predictor. Radial artery and gastroepiploic artery were more susceptible to graft deterioration. The susceptibilities of various graft materials to graft occlusion or string sign have not yet been fully determined, but in our study ITA grafts were apparently resistant to graft deterioration. Multiple grafts originating from a single inflow source were susceptible to graft deterioration. In this study, complex design, such as 


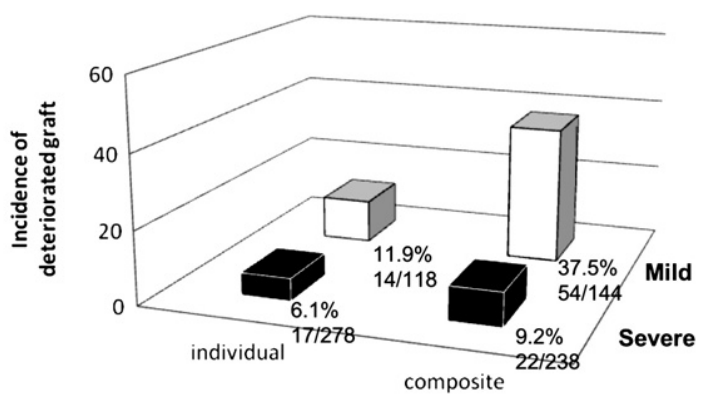

A

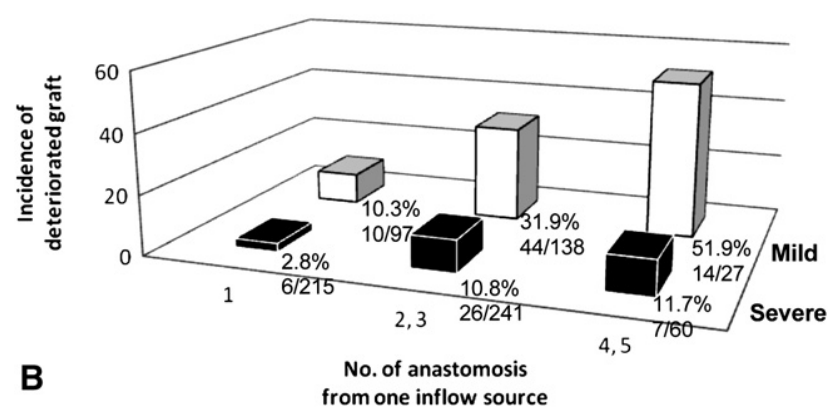

FIGURE 1. Effects of graft configuration (A) and number of distal anastomoses from single inflow source (B) on incidence of arterial graft deterioration according to severity of target coronary artery stenosis.

composite grafting and sequential multiple grafting, appeared to have certain pitfalls, although several studies have reported excellent patency rates for such grafts. ${ }^{16,17}$ When planning these types of grafts, selection of the target coronary artery is considered extremely important. For the target with mild stenosis, these types of grafts would result in a high failure rate, and individual grafts should be selected instead. This finding is in agreement with a previous study ${ }^{18}$ that demonstrated reduced blood flow in a composite graft used for a less stenosed target. On the other hand, patient characteristics and postoperative medications were not related to graft deterioration. These results enhance the importance of graft design in the prevention of graft deterioration in multiple arterial revascularization procedure.

\section{Clinical Significance of Graft Deterioration}

There is no consensus regarding the clinical significance of graft deterioration, especially of a graft showing string sign. There have been several case studies ${ }^{19,20}$ in which arterial grafts showing string sign regained patency after progression of native coronary artery stenosis. Furthermore, arterial grafts showing string sign can increase graft flow in response to a hyperemic situation, which suggests the capacity to meet the blood flow demand and to function as a bypass conduit. ${ }^{21,22}$ Several studies, however, have suggested poor angiographic outcomes of grafts showing string sign. Kim and colleagues ${ }^{12}$ reported that among 20 grafts initially FitzGibbon grade B, 12 grafts remained grade B and 3 grafts were occluded 3 years after surgery. Nakajima and coworkers ${ }^{7}$ reported that $71.4 \%$ of the bypasses with competitive or reversed flow at early angiography were occluded 3 years after surgery. Our study revealed that patients with deteriorated grafts were more likely to have ischemic symptoms. There have been no reports investigating the long-term consequences of grafts showing string signs, and further investigation is required.

\section{Mechanism of Graft Deterioration}

The mechanism of arterial graft deterioration is suggested by several previous studies. Arterial remodeling is a wellknown physiologic adaptation that occurs in response to long-term changes in blood flow to normalize shear stress. ${ }^{23}$ For ITA grafts, animal studies have demonstrated that a lowflow condition results in a decreased diameter of the artery accompanied by medial thickening within several months. ${ }^{24}$ These findings suggest that the deterioration of an arterial graft may be induced by a low-flow condition, and several clinical studies supported this hypothesis. Akasaka and associates $^{21}$ investigated the flow dynamics of the ITA graft showing string sign by use of a Doppler guide wire and demonstrated to and fro signals with systolic reversal and diastolic antegrade flow. Shimizu and coworkers ${ }^{25}$ demonstrated decreased graft diameter in a graft with low-flow condition. Tokuda and colleagues ${ }^{26}$ reported that a lower mean graft flow and a higher percentage of backward flow as measured by intraoperative transit time flow were independent risk factors for arterial graft deterioration. The results of our study are in agreement with these findings. Graft designs that might decrease the flow at distal anastomoses were revealed to be risk factors for arterial graft deterioration. Mild stenosis of the target coronary artery promotes flow competition. Multiple grafting from a single inflow source may limit the inflow volume and result in decreased graft flow. These findings suggest that a certain amount of graft flow is required to maintain the function of the arterial graft.

\section{Study Limitations}

This study has several limitations. First, all data were retrospectively collected, which may have led to information bias. Second, follow-up angiography was performed for only $47.8 \%$ of the patients who underwent off-pump CABG during this study period. Angiography was performed according to a protocol and was not symptom directed. We cannot eliminate the possibility that there was a bias in the patient selection. The patient characteristics and the midterm clinical results are compared between the study patients and the excluded patients in Table 3 . The differences need to be considered in the interpretation of our data. Importantly, the survival of the study patients was significantly higher than that of the excluded patients. This finding suggests that the rate of arterial graft deterioration may have been understated in our cohort, which was biased 
toward healthier patients. Third, the study patients included those with arterial grafts showing focal stenosis (11 instances of distal stenosis in 9 patients) on early angiography. The 11 grafts with focal stenosis seemed to have good graft flow on early angiography. At 1-year angiography, stenosis had disappeared in 5 grafts, and 6 grafts continued to show focal stenosis. None of the grafts with focal stenosis had graft deterioration. Fourth, the use of secondary preventive medication in the study patients was relatively low. Although postoperative medication was not statistically associated with the development of graft deterioration, it is possible that this low use of secondary prevention medication enhanced the development of graft deterioration.

\section{CONCLUSIONS}

Arterial graft deterioration 1 year after CABG occurred in $13.8 \%$ of all distal anastomoses in arterial grafts. The graft deterioration was closely related to particular graft materials and designs. The incidence of graft deterioration was higher for non-ITA grafts, non-LAD anastomoses, mild $(\leq 75 \%)$ stenosis of target coronary arteries, composite grafting, and multiple anastomoses from a single inflow source. The incidence was particularly high when composite or multiple grafting from a single inflow source was performed to a target coronary artery with mild stenosis. When performing multiple arterial grafting, careful attention to the selection of graft material and design is important to gain the full advantage of arterial grafts.

\section{References}

1. Loop FD, Lytle BW, Cosgrove DM, Stewart RW, Goormastic M, Williams GW, et al. Influence of the internal-mammary-artery graft on 10-year survival and other cardiac events. N Engl J Med. 1986;314:1-6.

2. Lytle BW, Blackstone EH, Loop FD, Houghtaling PL, Arnold JH, Akhrass R, et al. Two internal thoracic artery grafts are better than one. J Thorac Cardiovasc Surg. 1999;117:855-72.

3. Taggart DP, D'Amico R, Altman DG. Effect of arterial revascularization on survival: a systematic review of studies comparing bilateral and single internal mammary arteries. Lancet. 2001;358:870-5.

4. Zacharias A, Schwann TA, Riordan CJ, Durham SJ, Shah AS, Habib RH. Late results of conventional versus all-arterial revascularization based on internal thoracic and radial artery grafting. Ann Thorac Surg. 2009;87:19-26.

5. Lytle BW, Loop FD, Cosgrove DM, Ratliff NB, Easley K, Taylor PC. Long-term (5 to 12 years) serial studies of internal mammary artery and saphenous vein coronary bypass grafts. J Thorac Cardiovasc Surgery. 1985;89:248-58.

6. Cameron A, Davis KB, Green G, Schaff HV. Coronary bypass surgery with internal-thoracic-artery grafts-effects on survival over a 15-year period. $N$ Engl J Med. 2001;38:131-5.
7. Nakajima H, Kobayashi J, Tagusari O, Niwaya K, Funatsu T, Kawamura A, et al. Angiographic flow grading and graft arrangement of arterial conduits. $J$ Thorac Cardiovasc Surg. 2006;132:1023-9.

8. Sabik JF, Lytle BW, Blackstone EH, Khan M, Houghtaling PL, Cosgrove DM. Does competitive flow reduce internal thoracic artery graft patency? Ann Thorac Surg. 2003;76:1490-7.

9. Bezon E, Choplain JN, Maguid YA, Aziz AA, Barra JA. Failure of internal thoracic artery grafts: conclusions from coronary angiography mid-term follow-up. Ann Thorac Surg. 2003;76:754-9.

10. Desai ND, Cohen EA, Naylor CD, Fremes SE. A randomized comparison of radial-artery and saphenous-vein coronary bypass grafts. $N$ Engl J Med. 2004;351: 2302-9.

11. Fukui T, Takanashi S, Hosoda Y, Suehiro S. Early and midterm results of offpump coronary artery bypass grafting. Ann Thorac Surg. 2007;83:115-9.

12. Kim KB, Cho KR, Jeong DS. Midterm angiographic follow-up after off-pump coronary artery bypass: serial comparison using early, 1-year, and 5-year postoperative angiograms. J Thorac Cardiovasc Surg. 2008;135:300-7.

13. Tatoulis J, Buxton BF, Fuller JA. Patencies of 2127 arterial to coronary conduits over 15 years. Ann Thorac Surg. 2004;77:93-101.

14. Hashimoto H, Isshiki T, Ikari Y, Hara K, Saeki F, Tamura T, et al. Effects of competitive blood flow on arterial patency and diameter. Medium-term postoperative follow-up. J Thorac Cardiovasc Surg. 1996;111:399-407.

15. Miwa S, Desai N, Koyama T, Chan E, Cohen EA, Fremes SE. Radial artery angiographic string sign: clinical consequences and the role of pharmacologic therapy. Ann Thorac Surg. 2006;81:112-9.

16. Calafiore AM, Contini M, Vitolla G, Di Mauro M, Mazzei V, Tedori G, et al. Bilateral internal thoracic artery grafting: long-term clinical and angiographic results of in situ versus Y grafts. J Thorac Cardiovasc Surg. 2000; 120:990-8.

17. Nakajima H, Kobayashi J, Funatsu T, Shimahara Y, Kawamura M, Kawamura A, et al. Predictive factors for the intermediate-term patency of arterial grafts in aorta no-touch off-pump coronary revascularization. Eur J Cardiothorac Surg. 2007; 32:711-7.

18. Markwirth T, Hennen B, Scheller B, Schafers HJ, Wendler O. Flow wire measurements after complete arterial coronary revascularization with T-grafts. Ann Thorac Surg. 2001;71:788-93.

19. Siebenmann R, Egloff L, Hirzel H, Rothlin M, Studer M, Tartini R. The interna mammary artery 'string phenomenon'. Analysis of 10 cases. Eur J Cardiothorac Surg. 1993;7:235-8.

20. Merlo M, Terzi A, Tespili M, Ferrazzi P. Reversal of radial artery 'string sign' at 6 months follow-up. Eur J Cardiothorac Surg. 2003;23:432-4.

21. Akasaka T, Yoshida K, Hozumi T, Takagi T, Kaji S, Kawamoto T, et al. Flow dynamics of angiographically no-flow patent internal mammary artery grafts. $J \mathrm{Am}$ Coll Cardiol. 1998;31:1049-56.

22. Hartman J, Kelder H, Ackerstaff R, van Swieten H, Vermeulen F, Bogers A Preserved hyperaemic response in (distal) string sign left internal mammary artery grafts. Eur J Cardiothorac Surg. 2007;31:283-9.

23. Barner HB. Remodeling of arterial conduits in coronary grafting. Ann Thorac Surg. 2002;73:1341-5.

24. Kouchi Y, Onuki Y, Wu MH, Shi Q, Sauvage LR. Effect of altered blood flow on the caliber and morphology of the internal thoracic artery in the dog. $J$ Thorac Cardiovasc Surg. 1997;113:114-20.

25. Shimizu T, Hirayama T, Suesada H, Ikeda K, Ito S, Ishimaru S. Effect of flow competition on internal thoracic artery graft: postoperative velocimetric and angiographic study. J Thorac Cardiovasc Surg. 2000;120:459-65.

26. Tokuda Y, Song MH, Oshima H, Usui A, Ueda Y. Predicting midterm coronary artery bypass graft failure by intraoperative transit time flow measurement. Ann Thorac Surg. 2008;86:532-6. 